OPEN ACCESS

Edited by:

Carlo Alviggi,

University of Naples Federico II, Italy

Reviewed by:

Konstantinos Tziomalos,

Aristotle University of

Thessaloniki, Greece

Natascha Schweighofer

Medical University of Graz, Austria

*Correspondence:

Stephen L. Atkin

sla2002@qatar-med.cornell.edu

Specialty section:

This article was submitted to

Reproduction

a section of the journal

Frontiers in Endocrinology

Received: 12 March 2019 Accepted: 11 September 2019 Published: 25 September 2019

Citation:

Al-Hail N, Butler AE, Dargham SR, Abou Seif A and Atkin SL (2019)

Creatine Kinase Is a Marker of Metabolic Syndrome in Qatari Women With and Without Polycystic Ovarian Syndrome. Front. Endocrinol. 10:659. doi: 10.3389/fendo.2019.00659

\section{Creatine Kinase Is a Marker of Metabolic Syndrome in Qatari Women With and Without Polycystic Ovarian Syndrome}

\author{
Noora Al-Hail ${ }^{1}$, Alexandra E. Butler ${ }^{2}$, Soha R. Dargham ${ }^{3}$, Ahmed Abou Seif ${ }^{4}$ and \\ Stephen L. Atkin ${ }^{\text {* }}$
}

${ }^{1}$ Research Faculty, Weill Cornell Medicine, Doha, Qatar, ${ }^{2}$ Diabetes Research Center, Qatar Biomedical Research Institute, Hamad Bin Khalifa University, Qatar Foundation, Doha, Qatar, ${ }^{3}$ Infectious Disease Epidemiology Group, Weill Cornell Medicine, Doha, Qatar, ${ }^{4}$ Department of Obstetrics, Hamad Medical Corporation, Doha, Qatar

Objective: To correlate features of metabolic syndrome with creatine kinase (CK) in women with and without polycystic ovary syndrome (PCOS).

Design: Comparative cross-sectional analysis.

Methods: Demographic and metabolic data from Qatari women aged 18-40 years from the Qatar Biobank (97 diagnosed with PCOS, 563 controls). The primary outcome was the association between plasma CK and features of metabolic syndrome.

Results: CK increased when the waist circumference was $>80 \mathrm{~cm}(p<0.015)$ and when associated with 2 or more features of the metabolic syndrome $(p<0.01)$. CK correlated with BMI $(p<0.003)$ but not with waist/hip ratio. Overall, CK did not differ between PCOS and controls, rising equally in both as body mass index (BMI) increased. $C$ reactive protein $(\mathrm{CRP})$ was higher in obese PCOS $(P<0.05)$ compared to controls, but did not correlate with CK $(p>0.05)$.

Conclusion: CK was associated with an increase in BMI, waist circumference $>80 \mathrm{~cm}$ and 2 or more features of the metabolic syndrome, in accord with the central role of type II skeletal muscle fibers in energy metabolism and obesity. CK was, however, independent of the PCOS phenotype.

\section{Keywords: polycystic ovarian syndrome, creatine kinase, inflammation, obesity, metabolic syndrome}

\section{INTRODUCTION}

Polycystic ovarian syndrome (PCOS) is the most prevalent endocrine disorder affecting women of reproductive age (1), the prevalence in western populations estimated to be between 6 and $10 \%$ depending upon the diagnostic criteria used $(2,3)$, but is much higher in the Qatari population in the Middle East (4). The condition is characterized by disruption of the menstrual cycle with oligo- or amenorrhea, hyperandrogenism often presenting with acne, seborrhea, and/or hirsutism, and polycystic ovaries (5-7). PCOS is accompanied by a higher incidence of hypertension, insulin resistance and lipid profile abnormalities, resulting in an adverse cardiovascular profile (8-12); a higher prevalence of glucose dysregulation, manifesting as impaired fasting glucose or type 2 diabetes $(13,14)$; and obesity. However, it is recognized that within the PCOS phenotype there are a number of different androgenic and insulin resistant profiles $(15,16)$. 
Skeletal muscle may contribute to the development of obesity $(17,18)$, particularly the type II muscle fibers $(17,19)$. The reason for this is the type II muscle fibers are associated with fatty acid storage in adipose tissue (20), due to their low glucose uptake and reduced mitochondrial oxidation $(17,20)$. In addition, under normal conditions, skeletal muscle mediates the majority of insulin-stimulated whole-body glucose disposal, and inflammation of muscle with its dysregulation leading to increased insulin resistance is seen in obesity (21). CK is found in high levels in the type II fibers and may be used as a surrogate marker of skeletal muscle fiber number (18, 22). Studies have shown an association between CK and BMI, waist circumference and waist/hip ratio, suggesting that $\mathrm{CK}$ is a marker of obesity (18), and with the suggestion that it may identify individuals at risk of obesity (18). The aim of this study was to determine if CK was related to obesity and metabolic syndrome in this Middle Eastern population and whether CK was higher in those women with PCOS, perhaps due to elevated inflammatory markers (23-27), including C-reactive protein (CRP) (28).

\section{MATERIALS AND METHODS}

\section{Subjects}

This study was undertaken using data obtained from the national Qatar Biobank (QBB) (http://www.qatarbiobank.org. qa). The Qatar Biobank (QBB) was established as a longterm research initiative to benefit the population of Qatar. Adult Qatari men and women years are recruited to undergo a detailed clinical, biochemical and genetic data collection (approved by both the QBB institutional review board (IRB), and by the Ministry of Health Qatar). All participants gave written informed consent for their data and samples to be used in research.

This cross-sectional study involved 660 women between the ages of 18-40 years, 97 with PCOS and 563 control subjects. The diagnosis of PCOS was based upon the NIH criteria of biochemical evidence of hyperandrogenemia (free androgen index >4.5) and oligomenorrhea or amenorrhea; all had information to exclude other confounding diagnoses including thyroid function tests, prolactin, and 17 beta hydroxyprogesterone. All identified PCOS subjects had no documented concurrent illness and were not on any medication. All of the control women reported regular menses, had no biochemical hyperandrogenemia, no documented medical history, nor were they taking any medications. No subject had undertaken exercise in the preceding 3 days prior to sample collection.

Height, weight, waist circumference and body mass index (BMI) were collected according to $\mathrm{WHO}$ guidelines and Pulse Wave Velocity (PMV) was measured using VICORDER ${ }^{\circledR}$ PC 400 300E (SMT medical GmbH \& Co. KG, Wuerzburg, Germany) as reported previously $(4,29)$.

All methods of analysis were performed in accordance with the relevant guidelines and regulations with appropriate quality control.

\section{Collection and Analysis of Blood Samples}

After collection, blood samples were immediately processed (within $5 \mathrm{~min}$ ) and stored at $-80^{\circ} \mathrm{C}$ pending analysis. General chemistry assays and creatine kinase were analyzed by the National Center for Cancer Care, Doha, Qatar, using a Roche Cobas analyzer (Roche Diagnostics, PO Box 50457, Indianapolis, USA), whilst immunoassays were performed for $\mathrm{TSH}$, prolactin, insulin, testosterone, $\mathrm{C}$ reactive protein (CRP), DHEAS, and SHBG using an Abbott Architect analyzer (Abbott Laboratories, Abbott Park, Illinois, USA) using the manufacturer's recommended protocol. The functional sensitivity of the testosterone assay was $0.49 \mathrm{nmol} / \mathrm{L}$ with intraand inter-assay coefficients of variation for the assay of 10.0 and $11.3 \%$, respectively. The free androgen index (FAI) was calculated as the total testosterone $\times 100 /$ SHBG. Serum insulin was assayed using an Abbott Architect analyzer. The analytical sensitivity of the insulin assay was $2 \mu \mathrm{U} / \mathrm{ml}$, the coefficient of variation was $6 \%$, and there was no stated cross-reactivity with proinsulin. Plasma glucose was measured using a Roche Cobas analyzer. The coefficient of variation for the assay was $1.2 \%$ at a mean glucose value of $5.3 \mathrm{mmol} / \mathrm{L}$ during the study period. The insulin resistance was calculated using the HOMA method

TABLE 1 | Demographic details for 660 women between the ages of 18-40 years, comparing normal subjects with women defined as having polycystic ovary syndrome by NIH criteria (free androgen index $>4.5$ and/or a total testosterone $>2.7 \mathrm{nmol} / \mathrm{l}$, with irregular menses).

\begin{tabular}{|c|c|c|c|}
\hline & Control $(N=563)$ & $\operatorname{Pcos}(N=97)$ & $P$-value ${ }^{a}$ \\
\hline & Mean (SD) & Mean (SD) & \\
\hline Age (years) & $29.30(6.00)$ & $28.13(5.84)$ & 0.076 \\
\hline High Density lipoprotein (mmol/l) & $1.57(0.36)$ & $1.32(0.3)$ & $<0.001$ \\
\hline Systolic blood pressure (mmHg) & $104.71(10.97)$ & 108.69 (10.92) & 0.003 \\
\hline Diastolic blood pressure $(\mathrm{mmHg})$ & $68.83(9.33)$ & $72.64(8.06)$ & 0.001 \\
\hline $\mathrm{BMI}\left(\mathrm{kg} / \mathrm{m}^{2}\right)$ & $26.47(6.14)$ & $31.25(10.04)$ & $<0.001$ \\
\hline WBC & $6.65(1.73)$ & $7.52(1.92)$ & $<0.001$ \\
\hline Cholesterol (mmol/l) & $4.67(0.71)$ & $4.76(0.77)$ & 0.236 \\
\hline FPG $(\mathrm{mmol} / \mathrm{l})$ & $4.75(0.38)$ & $5.02(0.95)$ & $<0.01$ \\
\hline
\end{tabular}

\begin{tabular}{lccc}
\hline & Median (range) & Median (range) & $\boldsymbol{P}$-value $^{\mathbf{b}}$ \\
\hline Creatine Kinase IU/L & $62(1,811)$ & $65(223)$ & 0.562 \\
Weight (Kg) & $65.4(109.1)$ & $78.8(72.3)$ & $<0.001$ \\
Waist (cm) & $77.0(82.0)$ & $88.0(57.0)$ & $<0.001$ \\
Waist/Hip ratio & $0.73(0.44)$ & $0.79(0.40)$ & $<0.001$ \\
HbA1c (\%) & $5.2(9.4)$ & $5.4(6.6)$ & $<0.001$ \\
Insulin ( $\mu$ IU/ml) & $7.90(87.00)$ & $13.00(110.00)$ & $<0.001$ \\
Insulin resistance (HOMA-IR) & $1.8(263.8)$ & $2.6(32.1)$ & $<0.001$ \\
Low density lipoprotein (mmol/I) & $2.8(5.0)$ & $2.9(3.2)$ & 0.652 \\
Testosterone (nmol/I) & $1.1(2.3)$ & $1.7(5.8)$ & $<0.001$ \\
C-reactive protein (mmol/I) & $5.0(50.0)$ & $5.0(36.0)$ & $<0.001$ \\
FAl & $1.52(3.87)$ & $5.86(15.43)$ & $<0.001$ \\
Pulse wave velocity & $9.7(2.3)$ & $10.0(1.9)$ & 0.03 \\
\hline
\end{tabular}

a T-test used.

${ }^{b}$ Mann-Whitney test. 
[HOMA-IR $=($ insulin $\times$ glucose $) / 22.5]$. Data were supplied to Weill Cornell Medicine Qatar biostatistics (WCMQ) unit from the $\mathrm{QBB}$ in an anonymous coded manner that had been approved by the WCMQ IRB.

The BMI of each subject was stratified according to widely accepted criteria: normal $<25 \mathrm{~kg} / \mathrm{m}^{2}$, overweight $25-29.9 \mathrm{~kg} / \mathrm{m}^{2}$, obese $>30 \mathrm{~kg} / \mathrm{m}^{2}$.

\section{Data Analysis}

The level of significance was set at 5\%. Data trends were visually and statistically evaluated for normality. Independent $T$-tests were applied on normally distributed data, while non-parametric tests (Mann Whitney $U$ ) were applied on data that violated the assumptions of normality when tested using the Kolmogorov-Smirnov Test. Statistical analysis was performed using SPSS for Windows, version 24.0. Correlations between $\mathrm{CK}$ and demographic parameters were undertaken with Pearson's coefficient, and between CK and CRP with Spearman's coefficient.

\section{RESULTS}

\section{Demographic Data}

The PCOS and control groups were matched for age (Table 1). All subjects were non-diabetic.

The numbers of control and PCOS women in the normal BMI group were 279 (94.9\%) and 15 (5.1\%), respectively. The numbers of controls and PCOS women in the overweight group were 197 (90.8\%) and 20 (9.2), respectively. The number of control and PCOS in the obese group were 165 (79.3\%) and 43 (20.7\%), respectively.

\section{Creatine Kinase and Metabolic Syndrome (Figure 1)}

The parameters of metabolic syndrome were defined by that of the International Diabetes Federation (30); waist circumference $>80 \mathrm{~cm}, \mathrm{HDL}<1.3 \mathrm{mmol} / \mathrm{l}(50 \mathrm{mg} / \mathrm{dl})$, blood pressure $>130 / 85$ $\mathrm{mmHg}$, triglycerides $>1.7 \mathrm{mmol} / \mathrm{l}(150 \mathrm{mg} / \mathrm{dl})$, fasting plasma glucose $5.6 \mathrm{mmol} / \mathrm{l}(11 \mathrm{mg} / \mathrm{dl})$. When waist circumference less than or greater than $80 \mathrm{~cm}$ was compared [median (interquartile range; IQR)] CK was significantly increased (59(34) vs. $65(38) \mathrm{IU})$. Combining the remaining metabolic syndrome parameters (Table 2), CK showed no difference between 0 and 1 parameters [59(32) and 60(37)IU] but increased significantly when 2 or more parameters were combined [70(40) and 70(35) IU, respectively].

There was no overall difference in CK between the PCOS and control subjects when all subjects were included ( $p$ $=\mathrm{ns}$ ); nor was there a difference when the subjects were stratified according to BMI (Table 3). BMI increase was reflected in the increased waist circumference (Table 3). CRP was higher in those obese subjects with PCOS compared to controls $(p<0.02)$ but CRP was not associated with CK (Pearson's correlation between CK and CRP $R=0.022 ; P=0.560)$.

\section{Pulse Wave Velocity (PWV)}

Pulse wave velocity was significantly higher in PCOS compared to controls (Table 1) but using Spearman's correlations, CK and PWV were not significantly correlated. For the overall sample (Control + PCOS), $\mathrm{R}=-0.021(P=0.576)$. Taking the PCOS sample alone, $R=0.035(P=0.741)$; for the Control sample alone, $\mathrm{R}=-0.023(P=0.608)$.

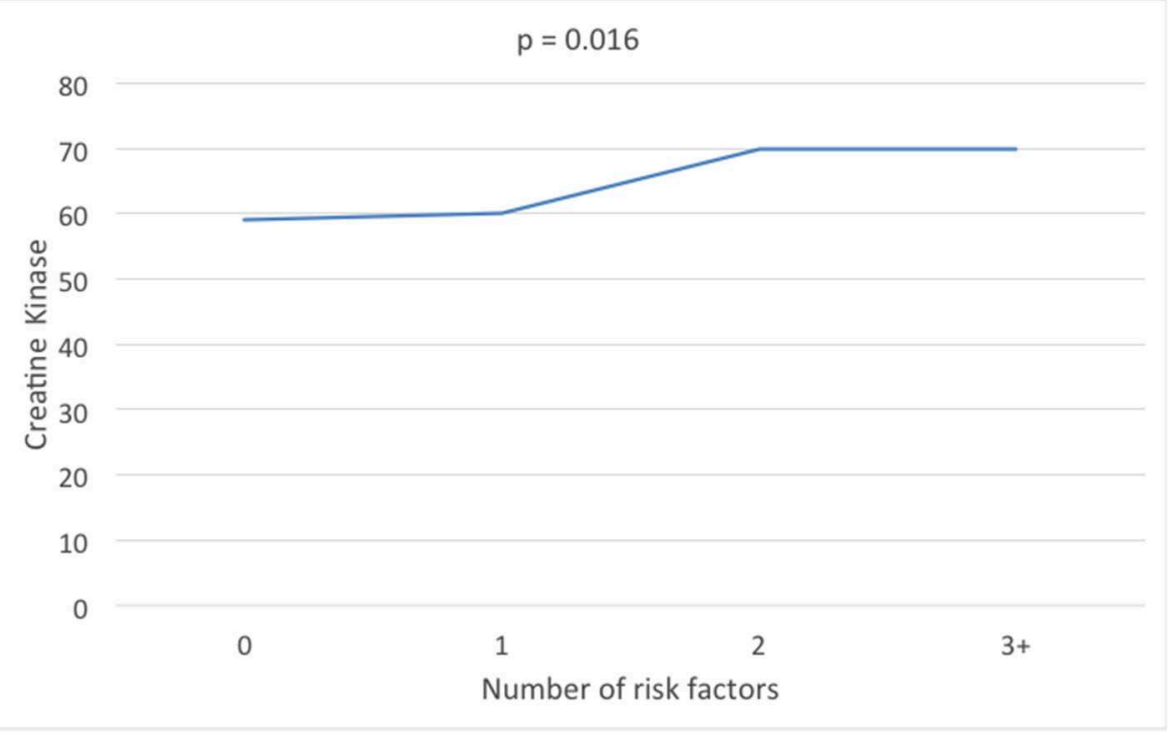

FIGURE 1 | Creatine kinase levels according to the number of metabolic syndrome parameters of high density lipoprotein, triglycerides, fasting plasma glucose, and blood pressure. 


\section{DISCUSSION}

This study demonstrates that, in this Qatari population, CK was associated with BMI, waist circumference and metabolic syndrome parameters, but that PCOS did not exacerbate the CK levels as they did not differ between PCOS and controls. These data are in accord with a previous study that showed an association of CK levels with BMI and waist circumference (18)

TABLE 2 | Categorization of the differing metabolic syndrome parameters.

\begin{tabular}{lcc}
\hline & N & $\%$ \\
\hline Waist Circumference and HDL & & \\
Low WC $(<80)$ and low HDL $(<1.29)$ & 57 & 7.70 \\
Low WC $(<80)$ and high HDL $(>1.29)$ & 364 & 49.00 \\
High WC $(>80)$ and low HDL $(<1.29)$ & 138 & 18.60 \\
High WC $(>80)$ and high HDL $(>1.29)$ & 184 & 24.80 \\
Waist Circumference and SBP & & \\
Low WC $(<80)$ and low SBP $(<130)$ & 419 & 56.20 \\
Low WC $(<80)$ and high SBP $(>130)$ & 4 & 0.50 \\
High WC $(>80)$ and low SBP $(<130)$ & 313 & 42.00 \\
High WC $(>80)$ and high SBP $(>130)$ & 9 & 1.20 \\
Waist Circumference and DBP & & \\
Low WC $(<80)$ and low DBP $(<85)$ & 414 & 55.60 \\
Low WC $(<80)$ and high DBP $(>85)$ & 9 & 1.20 \\
High WC $(>80)$ and low DBP $(<85)$ & 303 & 40.70 \\
High WC $(>80)$ and high DBP $(>85)$ & 19 & 2.60 \\
Waist Circumference and Glucose & & \\
Low WC $(<80)$ and low glucose $(<5.60)$ & 396 & 53.30 \\
Low WC $(<80)$ and high glucose $(>5.60)$ & 25 & 3.40 \\
High WC $(>80)$ and low glucose $(<5.60)$ & 268 & 36.10 \\
High WC $(>80)$ and low glucose $(>5.60)$ & 54 & 7.30 \\
\hline
\end{tabular}

The different metabolic syndrome parameters were defined as high WC $(\geq 80)$, low HDL ( $\leq 1.29)$, high SBP (>130), high $\mathrm{DBP}(>85)$, and low glucose $(\geq 5.6)$. Each of these five parameters were coded as 0 (not meeting the mentioned criteria) and 1 (for meeting the mentioned criteria). The metabolic syndrome score was a summation of these five parameters. To assess if a significant difference existed between the levels of metabolic syndrome, we used the Kruskall-Wallis test (CK was not normally distributed). The risk of higher CK was significantly associated $(p=0.014)$ with those with a sum of MTBS score of 2 compared to a score of 0. though in that study an association with waist hip ratio was found that was not seen here (18). This may be due to the racial mix of participants in that study compared to the homogeneous Qatari population studied here. However, in this study we showed that using the IDF definition of metabolic syndrome (30) with a waist circumference of $80 \mathrm{~cm}$ and 2 or more additional features that CK was significantly increased above this cut off. Because of this association, we sought to determine if $\mathrm{CK}$ was related to other components of the metabolic syndrome and showed that 2 or more parameters of the metabolic syndrome were associated with an increase in CK. Others have suggested that CK may be a marker for obesity $(17-19,31)$ given the correlation with BMI and waist circumference. However, waist circumference is a surrogate marker for cardiovascular disease, more so than BMI $(32,33)$, and the association with the additional composite measures of metabolic syndrome suggests that CK may be a surrogate marker for obesity and for cardiovascular risk.

The prevalence of metabolic syndrome has been shown to be higher in women with PCOS compared to control populations, with an overall pooled odds ratio of 2.09 in a recent meta-analysis (34), with a low high density lipoprotein (HDL), and high waist circumference being the most common components found. As noted above, given that waist circumference is a surrogate marker for cardiovascular disease, more so than $\operatorname{BMI}(32,33)$, and the association of a low HDL with cardiovascular disease, the evidence suggests that these issues need to be addressed in prevention strategies (34).

CRP is an inflammatory marker that is associated with cardiovascular risk $(28,35)$ and the significantly elevated levels in PCOS seen in this study are well-recognized (28). CRP was not, however, associated with creatine kinase, suggesting that the raised CK was likely not due to an increase in the inflammatory process, though other markers need to be measured to confirm this observation.

Pulse wave velocity reflects arterial stiffness that correlates well to cardiovascular risk. In young subjects (mean age 31 years) it has been suggested that this increased arterial stiffness may relate to greater blood pressure variability (36) that may in turn reflect increased cardiovascular risk. An increase in pulse wave velocity has been previously reported in PCOS (4). However, in this study, pulse wave velocity did not correlate with $\mathrm{CK}$,

TABLE 3 | The relationship between BMl categories to creatine kinase, C-reactive protein (CRP), and Waist circumference in subjects with and without PCOS stratified by body mass index.

\begin{tabular}{|c|c|c|c|c|c|c|c|c|c|}
\hline \multirow[t]{2}{*}{ BMI } & \multicolumn{2}{|c|}{$\begin{array}{c}\text { Creatine kinase (IU/L) } \\
\text { median (range) }\end{array}$} & \multirow[b]{2}{*}{$P$-value ${ }^{a}$} & \multicolumn{3}{|c|}{$\begin{array}{c}\text { CRP (mg/L) median } \\
\text { (range) }\end{array}$} & \multicolumn{3}{|c|}{$\begin{array}{c}\text { Waist circumference }(\mathrm{cm}) \\
\text { median (range) }\end{array}$} \\
\hline & Control & PCos & & Control & PCOS & $P$-value ${ }^{a}$ & Control & PCOS & $P$-value ${ }^{a}$ \\
\hline Normal & $\begin{array}{c}60 \\
(1,468)\end{array}$ & $\begin{array}{c}55 \\
(151)\end{array}$ & 0.359 & $\begin{array}{c}5.0 \\
(37.0)\end{array}$ & $\begin{array}{c}5.0 \\
(11.0)\end{array}$ & 0.167 & $\begin{array}{l}69.0 \\
(29.0)\end{array}$ & $\begin{array}{c}70.0 \\
(25.0)\end{array}$ & 0.175 \\
\hline Overweight & $\begin{array}{c}63 \\
(1,811)\end{array}$ & $\begin{array}{c}67 \\
(179)\end{array}$ & 0.205 & $\begin{array}{c}5.0 \\
(50.0)\end{array}$ & $\begin{array}{c}5.0 \\
(11.0)\end{array}$ & 0.077 & $\begin{array}{l}78.0 \\
(28.0)\end{array}$ & $\begin{array}{l}82.5 \\
(30.0)\end{array}$ & 0.005 \\
\hline Obese & $\begin{array}{c}66 \\
(290)\end{array}$ & $\begin{array}{c}65 \\
(223)\end{array}$ & 0.794 & $\begin{array}{c}5.0 \\
(44.0)\end{array}$ & $\begin{array}{c}9.0 \\
(36.0)\end{array}$ & 0.020 & $\begin{array}{c}89.0 \\
(53.0)\end{array}$ & $\begin{array}{c}95.0 \\
(38.0)\end{array}$ & 0.011 \\
\hline
\end{tabular}

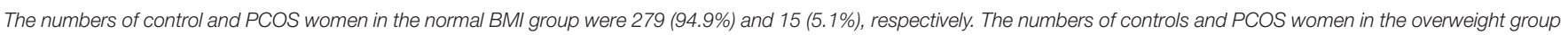
were 197 (90.8\%) and 20 (9.2), respectively. The number of control and healthy women in the obese group were 165 (79.3\%) and 43 (20.7\%), respectively.

a Kruskal-Wallis test. 
indicating, as expected, that the CK changes were not due to endothelial dysfunction.

$\mathrm{CK}$ is mainly derived from skeletal muscle and, in particular, the type II fibers that are associated with fatty acid storage in adipose tissue (20), due to their low glucose uptake and reduced mitochondrial oxidation $(17,20)$; it is of note that antioxidant supplementation seems to improve the reproductive outcome in PCOS patients $(37,38)$. Given that CK has been associated with obesity and insulin resistance (19, 39, 40 ), both features of the metabolic syndrome, then it is not surprising that the association was found in this group of subjects; however, the PCOS subjects here were even more insulin resistant with a higher BMI and waist circumference and it may have been expected that the CK would have been higher than controls, though this was not found. Thus, there appeared to be a threshold above which (3 or more metabolic syndrome parameters) CK did not show a further rise.

The strengths of the study are the use of biobank data and samples, that were collected in a highly standardized way, and that the study was done on a general population of Qatari women, that would have reduced any sex bias, and with relatively large numbers. As the subjects had not performed any exercise for 3 days prior to sampling, then this should have circumvented any exercise-induced CK rise. Whilst PCOS is recognized as being a heterogeneous condition, all of the subjects fulfilled the NIH criteria and in sufficient numbers to make the findings robust. Limitations of this study are that this was a cross-sectional retrospective study, with no direct measure of abdominal adipose tissue and with only CRP as an inflammatory marker, and a prospective interventional design would have been more powerful; also, the use of biobank data and samples limited the available data and sample types, preventing us from establishing the origin of the plasma CK. We did not have access to muscle biopsy tissue that may have identified the origin of the CK differences.

\section{REFERENCES}

1. Azziz R, Woods KS, Reyna R, Key TJ, Knochenhauer ES, Yildiz BO. The prevalence and features of the polycystic ovary syndrome in an unselected population. J Clin Endocrinol Metab. (2004) 89:2745-9. doi: 10.1210/jc.2003-032046

2. Legro RS, Arslanian SA, Ehrmann DA, Hoeger KM, Murad MH, Pasquali R, et al. Diagnosis and treatment of polycystic ovary syndrome: an endocrine society clinical practice guideline. J Clin Endocrinol Metab. (2013) 98:4565-92. doi: 10.1210/jc.2013-2350

3. Bozdag G, Mumusoglu S, Zengin D, Karabulut E, Yildiz BO. The prevalence and phenotypic features of polycystic ovary syndrome: a systematic review and meta-analysis. Hum Reprod. (2016) 31:2841-55. doi: 10.1093/humrep/dew218

4. Dargham SR, Ahmed L, Kilpatrick ES, Atkin SL. The prevalence and metabolic characteristics of polycystic ovary syndrome in the Qatari population. PloS One. (2017) 12:e0181467. doi: 10.1371/journal.pone.0181467

5. Rotterdam EA-SPCWG. Revised 2003 consensus on diagnostic criteria and long-term health risks related to polycystic ovary syndrome. Fertil Steril. (2004) 81:19-25. doi: 10.1016/j.fertnstert.2003.10.004
In conclusion, $\mathrm{CK}$ was associated with an increase in BMI, waist circumference $>80 \mathrm{~cm}$ and 2 or more features of the metabolic syndrome in accord with the central role of type II skeletal muscle fibers in energy metabolism and obesity. This effect was seen independent of the PCOS phenotype.

\section{DATA AVAILABILITY STATEMENT}

The datasets generated for this study are available on request to the corresponding author.

\section{ETHICS STATEMENT}

This study was undertaken using data obtained from the national QBB (http://www.qatarbiobank.org.qa). The Qatar Biobank (QBB) was established as a long-term research initiative to benefit the population of Qatar. Adult Qatari men and women years are recruited to undergo a detailed clinical, biochemical, and genetic data collection (approved by both the QBB institutional review board (IRB), and by the Ministry of Health Qatar). All participants gave written informed consent for their data and samples to be used in research in accordance with the Declaration of Helsinki.

\section{AUTHOR CONTRIBUTIONS}

NA-H drafted the first version, contributed, and approved the manuscript. $\mathrm{AB}$ and $\mathrm{AA}$ proof read the manuscript, contributed, and approved the manuscript. SD performed the statistical analysis, contributed, and approved the manuscript. SA conceived the study, performed data collation, and approved the manuscript.

\section{ACKNOWLEDGMENTS}

We are very grateful for the support for this work from the Qatar Biobank and the Qatar Foundation.

6. Norman RJ, Dewailly D, Legro RS, Hickey TE. Polycystic ovary syndrome. Lancet. (2007) 370:685-97. doi: 10.1016/S0140-6736(07)61345-2

7. Ehrmann DA. Polycystic ovary syndrome. New Engl J Med. (2005) 352:122336. doi: 10.1056/NEJMra041536

8. Sathyapalan T, Atkin SL. Recent advances in cardiovascular aspects of polycystic ovary syndrome. Euro J Endocrinol. (2012) 166:575-83. doi: 10.1530/EJE-11-0755

9. Moran L, Teede H. Metabolic features of the reproductive phenotypes of polycystic ovary syndrome. Human Reproduct Update. (2009) 15:477-88. doi: 10.1093/humupd/dmp008

10. Toulis KA, Goulis DG, Mintziori G, Kintiraki E, Eukarpidis E, Mouratoglou SA, et al. Meta-analysis of cardiovascular disease risk markers in women with polycystic ovary syndrome. Hum Reprod Update. (2011) 17:741-60. doi: 10.1093/humupd/dmr025

11. DeUgarte CM, Bartolucci AA, Azziz R. Prevalence of insulin resistance in the polycystic ovary syndrome using the homeostasis model assessment. Fertil Steril. (2005) 83:1454-60. doi: 10.1016/j.fertnstert.2004. 11.070

12. March WA, Moore VM, Willson KJ, Phillips DI, Norman RJ, Davies MJ. The prevalence of polycystic ovary syndrome in a community sample 
assessed under contrasting diagnostic criteria. Hum Reprod. (2010) 25:544-51. doi: 10.1093/humrep/dep399

13. Morgan CL, Jenkins-Jones S, Currie CJ, Rees DA. Evaluation of adverse outcome in young women with polycystic ovary syndrome versus matched, reference controls: a retrospective, observational study. J Clin Endocrinol Metab. (2012) 97:3251-60. doi: 10.1210/jc.2012-1690

14. Joham AE, Ranasinha S, Zoungas S, Moran L, Teede HJ. Gestational diabetes and type 2 diabetes in reproductive-aged women with polycystic ovary syndrome. J Clin Endocrinol Metab. (2014) 99:E447-52. doi: 10.1210/jc.2013-2007

15. Paschou SA, Palioura E, Ioannidis D, Anagnostis P, Panagiotakou A, Loi $\mathrm{V}$, et al. Adrenal hyperandrogenism does not deteriorate insulin resistance and lipid profile in women with PCOS. Endocrine Connect. (2017) 6:601-6. doi: 10.1530/EC-17-0239

16. Alviggi C, Conforti A, De Rosa P, Strina I, Palomba S, Vallone R, et al. The Distribution of stroma and antral follicles differs between insulinresistance and hyperandrogenism-related polycystic ovarian syndrome. Front Endocrinol. (2017) 8:117. doi: 10.3389/fendo.2017.00117

17. Tanner CJ, Barakat HA, Dohm GL, Pories WJ, MacDonald KG, Cunningham PR, et al. Muscle fiber type is associated with obesity and weight loss. Am J Physiol Endocrinol Metab. (2002) 282:E1191-6. doi: 10.1152/ajpendo.00416.2001

18. Haan YC, Oudman I, Diemer FS, Karamat FA, van Valkengoed IG, van Montfrans GA, et al. Creatine kinase as a marker of obesity in a multi-ethnic population. Mol Cell Endocrinol. (2017) 442:24-31. doi: 10.1016/j.mce.2016.11.022

19. Kriketos AD, Pan DA, Lillioja S, Cooney GJ, Baur LA, Milner $\mathrm{MR}$, et al. Interrelationships between muscle morphology, insulin action, and adiposity. Am J Physiol. (1996) 270(6 Pt 2):R1332-9. doi: 10.1152/ajpregu.1996.270.6.R1332

20. Schiaffino S, Reggiani C. Fiber types in mammalian skeletal muscles. Physiol Rev. (2011) 91:1447-531. doi: 10.1152/physrev.00031.2010

21. Wu H, Ballantyne CM. Skeletal muscle inflammation and insulin resistance in obesity. J Clin Invest. (2017) 127:43-54. doi: 10.1172/JCI88880

22. Yamashita K, Yoshioka T. Profiles of creatine kinase isoenzyme compositions in single muscle fibres of different types. J Muscle Res Cell Motil. (1991) 12:37-44. doi: 10.1007/BF01781172

23. Diamanti-Kandarakis E, Paterakis T, Alexandraki K, Piperi C, Aessopos A, Katsikis I, et al. Indices of low-grade chronic inflammation in polycystic ovary syndrome and the beneficial effect of metformin. Hum Reprod. (2006) 21:1426-31. doi: 10.1093/humrep/del003

24. Hu WH, Qiao J, Zhao SY, Zhang XW, Li MZ. [Monocyte chemoattractant protein-1 and its correlation with lipoprotein in polycystic ovary syndrome]. Beijing Da Xue Xue Bao Yi Xue Ban. (2006) 38:487-91.

25. Gonzalez F, Rote NS, Minium J, Kirwan JP. Reactive oxygen speciesinduced oxidative stress in the development of insulin resistance and hyperandrogenism in polycystic ovary syndrome. J Clin Endocrinol Metab. (2006) 91:336-40. doi: 10.1210/jc.2005-1696

26. Gonzalez F, Rote NS, Minium J, Kirwan JP. In vitro evidence that hyperglycemia stimulates tumor necrosis factor-alpha release in obese women with polycystic ovary syndrome. J Endocrinol. (2006) 188:521-9. doi: 10.1677/joe.1.06579

27. Gonzalez F, Minium J, Rote NS, Kirwan JP. Hyperglycemia alters tumor necrosis factor-alpha release from mononuclear cells in women with polycystic ovary syndrome. J Clin Endocrinol Metab. (2005) 90:5336-42. doi: 10.1210/jc.2005-0694

28. Escobar-Morreale HF, Luque-Ramirez M, Gonzalez F. Circulating inflammatory markers in polycystic ovary syndrome: a systematic review and metaanalysis. Fertil Steril. (2011) 95:1048-58.e1-2. doi: 10.1016/j.fertnstert.2010.11.036

29. Dargham SR, Shewehy AE, Dakroury Y, Kilpatrick ES, Atkin SL. Prediabetes and diabetes in a cohort of Qatari women screened for polycystic ovary syndrome. Sci Rep. (2018) 8:3619. doi: 10.1038/s41598-018-21987-6
30. Alberti KG, Eckel RH, Grundy SM, Zimmet PZ, Cleeman JI, Donato KA, et al. Harmonizing the metabolic syndrome: a joint interim statement of the international diabetes federation task force on epidemiology and prevention; national heart, lung, and blood institute; American heart association; world heart federation; international atherosclerosis society; and international association for the study of obesity. Circulation. (2009) 120:1640-5. doi: 10.14341/2071-8713-5281

31. Lapsys NM, Kriketos AD, Lim-Fraser M, Poynten AM, Lowy A, Furler $\mathrm{SM}$, et al. Expression of genes involved in lipid metabolism correlate with peroxisome proliferator-activated receptor gamma expression in human skeletal muscle. J Clin Endocrinol Metab. (2000) 85:4293-7. doi: $10.1210 /$ jc. 85.11 .4293

32. Klein S, Allison DB, Heymsfield SB, Kelley DE, Leibel RL, Nonas C, et al. Waist circumference and cardiometabolic risk: a consensus statement from Shaping America's Health: association for weight management and obesity prevention; NAASO, the obesity society; the American Society for Nutrition; and the American Diabetes Association. Am J Clin Nutri. (2007) 85:1197-202. doi: 10.1093/ajcn/85.5.1197

33. Myint PK, Kwok CS, Luben RN, Wareham NJ, Khaw KT. Body fat percentage, body mass index and waist-to-hip ratio as predictors of mortality and cardiovascular disease. Heart. (2014) 100:1613-9. doi: 10.1136/heartjnl-2014-305816

34. Hallajzadeh J, Khoramdad M, Karamzad N, Almasi-Hashiani A, Janati A, Ayubi E, et al. Metabolic syndrome and its components among women with polycystic ovary syndrome: a systematic review and metaanalysis. J Cardiovas Thor Res. (2018) 10:56-69. doi: 10.15171/jcvtr. 2018.10

35. van Wissen S, Trip MD, Smilde TJ, de Graaf J, Stalenhoef AF, Kastelein JJ. Differential hs-CRP reduction in patients with familial hypercholesterolemia treated with aggressive or conventional statin therapy. Atherosclerosis. (2002) 165:361-6. doi: 10.1016/S0021-9150(02)00280-0

36. Boardman H, Lewandowski AJ, Lazdam M, Kenworthy Y, Whitworth $\mathrm{P}$, Zwager CL, et al. Aortic stiffness and blood pressure variability in young people: a multimodality investigation of central and peripheral vasculature. J Hypertens. (2017) 35:513-22. doi: 10.1097/HJH.0000000000 001192

37. Alviggi C, Cariati F, Conforti A, De Rosa P, Vallone R, Strina I, et al. The effect of FT500 Plus((R)) on ovarian stimulation in PCOS women. Reprod Toxicol. (2016) 59:40-4. doi: 10.1016/j.reprotox.2015.10.014

38. Sadeghi F, Alavi-Naeini A, Mardanian F, Ghazvini MR, Mahaki B. Omega-3 and vitamin E co-supplementation can improve antioxidant markers in obese/overweight women with polycystic ovary syndrome. Int $J$ Vitam Nutr Res. (2019). doi: 10.1024/0300-9831/a000588. [Epub ahead of print].

39. Simoneau JA, Colberg SR, Thaete FL, Kelley DE. Skeletal muscle glycolytic and oxidative enzyme capacities are determinants of insulin sensitivity and muscle composition in obese women. FASEB J. (1995) 9:273-8. doi: 10.1096/fasebj.9.2.7781930

40. Simoneau JA, Bouchard C. Skeletal muscle metabolism and body fat content in men and women. Obes Res. (1995) 3:23-9. doi: 10.1002/j.1550-8528.1995.tb00117.x

Conflict of Interest: The authors declare that the research was conducted in the absence of any commercial or financial relationships that could be construed as a potential conflict of interest.

Copyright (C) 2019 Al-Hail, Butler, Dargham, Abou Seif and Atkin. This is an openaccess article distributed under the terms of the Creative Commons Attribution License (CC BY). The use, distribution or reproduction in other forums is permitted, provided the original author(s) and the copyright owner(s) are credited and that the original publication in this journal is cited, in accordance with accepted academic practice. No use, distribution or reproduction is permitted which does not comply with these terms. 